\title{
Testosterone Therapy and Diaphragm Performance in a Male Patient with COVID-19: A Case Report
}

\author{
Gloria Martins ${ }^{1,2}$, Juan Carlos Rosso Verdeal ${ }^{2}$, Helio Tostes ${ }^{2}$, Alice Ramos Oliveira da Silva ${ }^{2}{ }^{\circ}$, \\ Bernardo Tessarollo $^{2}$ (D), Nazareth Novaes Rocha ${ }^{1,3}$, Patricia Rieken Macedo Rocco ${ }^{1}$ (D) and Pedro Leme Silva ${ }^{1, *}$ \\ 1 Laboratory of Pulmonary Investigation, Institute of Biophysics Carlos Chagas Filho, \\ Federal University of Rio de Janeiro, Rio de Janeiro 21941-599, Brazil; gloria.martins@gmail.com (G.M.); \\ nn_rocha@hotmail.com (N.N.R.); prmrocco@gmail.com (P.R.M.R.) \\ 2 Barra D’Or, Rio de Janeiro 22775-002, Brazil; jverdeal@gmail.com (J.C.R.V.); htostesf@gmail.com (H.T.); \\ aliceramosoliveiradasilva@gmail.com (A.R.O.d.S.); btessa@gmail.com (B.T.) \\ 3 Department of Physiology, Fluminense Federal University, Niterói 24210-130, Brazil \\ * Correspondence: pedroleme@biof.ufr.j.br
}

\section{check for} updates

Citation: Martins, G.; Verdeal, J.C.R.; Tostes, H.; da Silva, A.R.O. Tessarollo, B.; Rocha, N.N.; Rocco, P.R.M.; Silva, P.L. Testosterone Therapy and Diaphragm Performance in a Male Patient with COVID-19: A Case Report. Diagnostics 2022, 12, 535. https: / / doi.org/10.3390/diagnostics12020535 Academic Editors: Denise Battaglini and Davide Orlandi

Received: 24 January 2022

Accepted: 17 February 2022

Published: 19 February 2022

Publisher's Note: MDPI stays neutral with regard to jurisdictional claims in published maps and institutional affiliations.

Copyright: (C) 2022 by the authors. Licensee MDPI, Basel, Switzerland. This article is an open access article distributed under the terms and conditions of the Creative Commons Attribution (CC BY) license (https:// creativecommons.org/licenses/by/ $4.0 /)$.

\begin{abstract}
Low levels of testosterone may lead to reduced diaphragm excursion and inspiratory time during COVID-19 infection. We report the case of a 38-year-old man with a positive result on a reverse transcriptase-polymerase chain reaction test for SARS-CoV-2, admitted to the intensive care unit with acute respiratory failure. After several days on mechanical ventilation and use of rescue therapies, during the weaning phase, the patient presented dyspnea associated with low diaphragm performance (diaphragm thickness fraction, amplitude, and the excursion-time index during inspiration were $37 \%, 1.7 \mathrm{~cm}$, and $2.6 \mathrm{~cm} / \mathrm{s}$, respectively) by ultrasonography and reduced testosterone levels (total testosterone, bioavailable testosterone and sex hormone binding globulin (SHBG) levels were $9.3 \mathrm{ng} / \mathrm{dL}, 5.8 \mathrm{ng} / \mathrm{dL}$, and $10.5 \mathrm{nmol} / \mathrm{L}$, respectively). Testosterone was administered three times 2 weeks apart (testosterone undecanoate $1000 \mathrm{mg} / 4 \mathrm{~mL}$ intramuscularly). Diaphragm performance improved significantly (diaphragm thickness fraction, amplitude, and the excursion-time index during inspiration were $70 \%, 2.4 \mathrm{~cm}$, and $3.0 \mathrm{~cm} / \mathrm{s}$, respectively) 45 and 75 days after the first dose of testosterone. No adverse events were observed, although monitoring was required after testosterone administration. Testosterone replacement therapy led to good diaphragm performance in a male patient with COVID-19. This should be interpreted with caution due to the exploratory nature of the study.
\end{abstract}

Keywords: testosterone; diaphragm; COVID-19

\section{Introduction}

Cross-sectional [1] and case-control [2] studies suggest an association between low testosterone levels and a systemic increase in inflammatory cells and mediators (neutrophils, procalcitonin, and ferritin) in cases of pneumonia induced by SARS-CoV-2. Reduced testosterone levels may be the result of a complex interaction between the host and the virus. During the hyperinflammatory acute phase, deregulation of gonadal function may occur, leading in some cases to transient hypogonadism [3-5]. In addition, low levels of testosterone may have a negative impact on skeletal muscle performance, particularly on the diaphragm. Diaphragm performance can be defined according to the excursiontime (E-T) index [6]. The E-T index takes into account diaphragm excursion, measured by ultrasonography, as a surrogate for mean tidal pressure (PI) generated by respiratory muscle multiplied by inspiratory time (TI) and as a proxy for the work performed by the diaphragm. Neuromuscular disorders may evolve in patients with COVID-19 [7], which may be caused by both the release of proinflammatory mediators [8] and the frequent use of myopathogenic medications, such as corticosteroid and neuromuscular blockers during the acute phase [9], as well as immobility. Testosterone supplementation can increase lean 
body mass [10], especially when combined with growth hormone [11]. In COVID-19, some studies have shown that the proinflammatory state that arises due to low testosterone levels can be suppressed with the provision of exogenous testosterone $[12,13]$. Thus, it remains unclear whether testosterone administration can have a clinical impact on skeletal muscle performance, mainly the diaphragm, during the weaning process after the acute phase of COVID-19.

\section{Case Study}

In carrying out this study, we followed the CARE guidelines (https:/ / www.carestatement.org/ (accessed on 10 January 2022)). Written informed consent was obtained from the patient to publish this paper. On 15 January 2021, a 38-year-old man with body mass index of $35 \mathrm{~kg} / \mathrm{m}^{2}$, with a positive result on a reverse transcriptase-polymerase chain reaction (RT-PCR) test for SARS-CoV-2 infection, was admitted to the intensive care unit (ICU) with acute respiratory failure. The patient was promptly intubated endotracheally and mechanically ventilated. After infusion with rocuronium bromide $(8 \mu \mathrm{g} / \mathrm{kg} / \mathrm{min})$, his $\mathrm{PaO}_{2} / \mathrm{FiO}_{2}$ (the ratio of arterial oxygen partial pressure to fractional inspired oxygen) was $83 \mathrm{mmHg}$, and a chest computed tomography scan showed bilateral diffuse consolidations and ground glass opacities over $50 \%$ of the total pulmonary area. No personal or family medical history of rhabdomyolysis, myoglobinuria, or any type of muscle disease was reported. The patient did not take statins or any myotoxic agents. The patient rapidly progressed to multiple organ dysfunction with renal replacement therapy, prone position ventilation, and nitric oxide inhalation. No clinical and oxygenation improvements were observed; therefore, extracorporeal membrane oxygenation (ECMO) was initiated. The patient was kept in ECMO for 12 days, followed by 19 days with a neuromuscular blocking agent (rocuronium bromide). In addition, the patient received midazolam and fentanyl for 43 days, dexmedetomidine for 6 days, methylprednisolone for 10 days, and amikacin sulfate for 30 days.

After sedation, anesthesia, and the neuromuscular blocking agent were withdrawn, the patient presented dyspnea associated with myalgia and fatigue, as well as severe proximal muscle weakness in both upper and lower limbs on clinical examination. Evaluation of segmental muscle strength showed diffuse and symmetrical weakness, as well as deep and superficial sensory disturbance. Flaccid tetraparesis and limb muscle atrophy were also observed. Creatine kinase level was not increased on laboratory examination. Neuroradiologic examinations were normal. Ultrasonography was used to measure (1) diaphragm muscle thickness fraction (thickness at inspiration - thickness at expiration/thickness at expiration) $\times 100$; (2) diaphragm amplitude excursion; (3) excursion-time index [6] during inspiration; and (4) rectus femoris muscle size and quality, as an internal control parameter. Using a validated technique, right diaphragm muscle thickness was measured using a high-frequency $(13 \mathrm{MHz})$ linear array transducer in the zone of apposition (assessed at $0.5-2 \mathrm{~cm}$ below the costophrenic sinus) between the anterior and midaxillary lines at the level of the 9th or 10th intercostal space [14]. The location of the placement of the ultrasonographic probe was marked to enhance consistency of the day-to-day measurements. The thickness of expiratory and inspiratory diaphragm muscle was measured on 2 consecutive breaths from 2 separate images. Measurements were repeated by the same investigator to ensure comparable measurements (defined as $<10 \%$ difference); the mean of all 4 measurements was used for analysis. On 23 February 2021, defined as the baseline, the patient was breathing spontaneously with supplemental oxygen by tracheostomy; diaphragm thickness fraction, amplitude, and the excursion-time index during inspiration were $37 \%, 1.7 \mathrm{~cm}$, and $2.6 \mathrm{~cm} / \mathrm{s}$, respectively. At this time, total testosterone, bioavailable testosterone and sex hormone binding globulin (SHBG) levels were $9.3 \mathrm{ng} / \mathrm{dL}, 5.8 \mathrm{ng} / \mathrm{dL}$, and $10.5 \mathrm{nmol} / \mathrm{L}$, respectively (Table 1 ). In addition, C-reactive protein and ferritin levels were $6.6 \mathrm{mg} / \mathrm{dL}$ and $1996 \mathrm{ng} / \mathrm{mL}$, respectively. Testosterone was administered 3 times 2 weeks apart (testosterone undecanoate $1000 \mathrm{mg} / 4 \mathrm{~mL}$ intramuscularly; NEBIDO, Bayer, Germany). Forty-five days after the first dose, the patient was decannulated and breathed 
spontaneously in room air. Table 1 and Figure 1 show the diaphragm thickness fraction, amplitude, and excursion-time index during inspiration, which improved after 45 days and sustained up to 75 days after the first dose of testosterone. Accordingly, total testosterone, bioavailable testosterone, and SHBG levels increased after 45 days and remained increased 75 days after the first dose of testosterone, just before hospital discharge. A progressive decrease in C-reactive protein and ferritin levels from baseline to 75 days after the first dose of testosterone can be observed. No major differences were observed in the size and quality of rectus femoris muscle over time.

Table 1. Diaphragm ultrasonography and blood laboratory measurements over time.

\begin{tabular}{cccc}
\hline & Baseline & After 45 Days & After 75 Days \\
\hline Diaphragm ultrasonography measurements & \\
Thickness at expiration (cm) & 0.30 & 0.31 & 0.30 \\
Thickness at inspiration (cm) & 0.41 & 0.51 & 0.51 \\
Thickness fraction (\%) & 37 & 67 & 70 \\
Blood laboratory & 2.6 & 2.4 & 3.0 \\
Excursion-time index during inspiration (cm/s) & 9.3 & 212 & 332 \\
Total testosterone (ng/dL) & 5.8 & 129 & 196 \\
Bioavailable testosterone $(\mathrm{ng} / \mathrm{dL})$ & 10.5 & 15.5 & 17.9 \\
Sex hormone binding globulin $(\mathrm{nmol} / \mathrm{L})$ & 0.5 & 0.5 & 0.4 \\
Total prostate-specific antigen $(\mathrm{ng} / \mathrm{mL})$ & 0.2 & 0.2 & 0.2 \\
Free prostate-specific antigen $(\mathrm{ng} / \mathrm{mL})$ & 6.6 & 5.4 & 2.2 \\
C-reactive protein $(\mathrm{mg} / \mathrm{dL})$ & 1996 & 1983 & 1041 \\
Ferritin $(\mathrm{ng} / \mathrm{mL})$ & & &
\end{tabular}
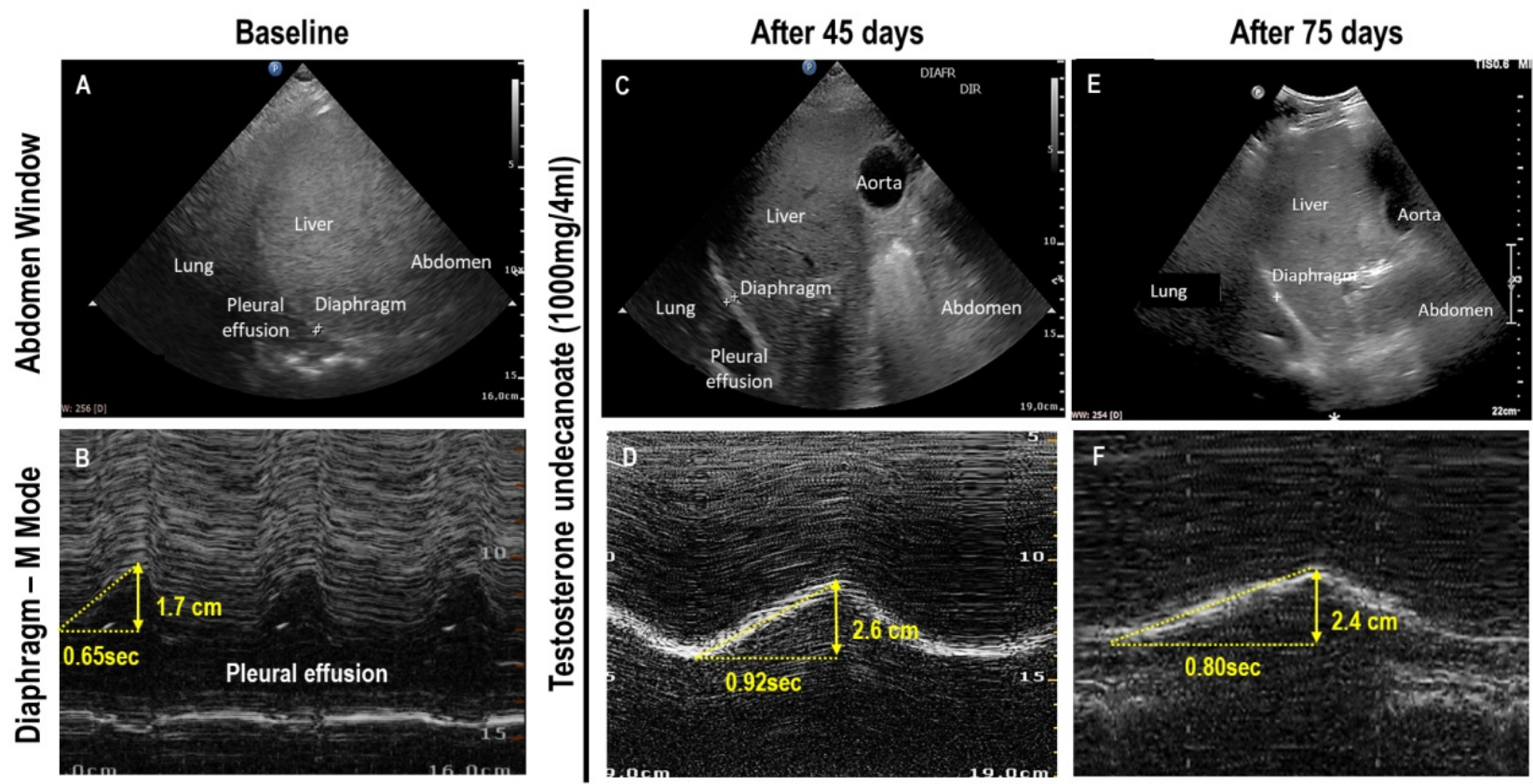

Figure 1. (A) Abdomen window at baseline showing extensive pleural effusion. (B) Diaphragm M-mode at baseline; diaphragm amplitude during inspiration $=1.7 \mathrm{~cm}$; diaphragm thickness fraction $=37 \%$; excursion-time index $=2.6 \mathrm{~cm} / \mathrm{s}$. Testosterone was administered 3 times 2 weeks apart (testosterone undecanoate $1000 \mathrm{mg} / 4 \mathrm{~mL}$ intramuscularly; NEBIDO, Bayer, Germany). (C) Abdomen window after 45 days. (D) Diaphragm M-mode after 45 days; diaphragm amplitude during inspiration $=2.6 \mathrm{~cm}$; diaphragm thickness fraction $=60 \%$; excursion-time index $=2.4 \mathrm{~cm} / \mathrm{s}$. $(\mathrm{E}) \mathrm{Ab}$ domen window after 75 days. (F) Diaphragm M-mode after 75 days; diaphragm amplitude during inspiration $=2.4 \mathrm{~cm}$; diaphragm thickness fraction $=50 \%$; excursion-time index $=3.0 \mathrm{~cm} / \mathrm{s}$. 
Thickness fraction $=($ thickness at inspiration - thickness at expiration $) /$ thickness at expiration $\times 100$. Baseline was defined as the time when the patient was breathing spontaneously with supplemental oxygen by tracheostomy. After 45 and 75 days, after the first dose of testosterone administration, testosterone was administered 3 times 2 weeks apart (testosterone undecanoate $1000 \mathrm{mg} / 4 \mathrm{~mL}$ intramuscularly; NEBIDO, Bayer, Germany). Normal total testosterone range (males $\geq 19$ years), $240-950 \mathrm{ng} / \mathrm{dL}$; normal bioavailable testosterone range (males 30-39 years), 72-235 ng/dL; normal sex hormone binding globulin range (males), 10-57 nmol/L; normal total prostate-specific antigen, below $4 \mathrm{ng} / \mathrm{mL}$; normal free prostate-specific antigen range (males 40-49 years), 0-2.5 ng/mL; normal C-reactive protein range, $0.8-100 \mathrm{mg} / \mathrm{dL}$; normal ferritin range, $20-250 \mathrm{ng} / \mathrm{mL}$.

\section{Discussion}

COVID-19 significantly affects more men than women [15]; however, there are controversies regarding the mechanisms. In this line, men are more prone to co-morbidities (e.g., smoke exposure) compared to women, even before the SARS-CoV2 pandemic [16]. In contrast, the $X$ chromosome contains several genes related to viral infections response, such as the toll-like receptor 7, which may confer innate immune protection in women [17]. Transmembrane protease serine 2 (TMPRSS2) is an androgen receptor, which together with angiotensin-converting enzyme (ACE)-2 promotes SARS-CoV2 invasion of host cells [18]. TMPRSS2 is also the most frequently altered gene in primary prostate cancer [19] and its expression is positively regulated by androgens, which may increase TMPRSS2 expression in the surface of bronchial respiratory cells and promote a wide gate to host infection by SARSCoV2 [20]. Theoretically, men with low levels of androgens would be protected against SARS-CoV2 infection, but this is not observed. Cross-sectional [1] and case-control [2] studies suggest an association between low testosterone levels and blood inflammatory cells and markers of the severity of SARS-CoV-2 pneumonia, such as neutrophils, procalcitonin, and ferritin. The inflammatory cytokine storm may induce muscle weakness by at least four processes: (1) initial myofibrillar protein cleavage by activated caspase-3; (2) degradation by the ubiquitin-proteosome system; (3) interruption of muscle protein synthesis through inhibition of mammalian target of rapamycin complex 1 (mTORc1), which impairs muscle turnover; and (4) deregulation of muscle growth hormones, such as insulin-like growth factor (IGF)-1.

Testosterone supplementation can increase lean body mass, although a recent clinical trial showed no effect on lower-body muscle function [10]. Nevertheless, testosterone combined with growth hormone resulted in substantial gains in lean mass, voluntary muscle strength, and aerobic endurance compared with testosterone alone [11]. The increase in muscle function may depend on the deficits that occurred before intervention, in this case, exogenous testosterone administration. In COVID-19, some studies have shown that the proinflammatory state that arises due to low testosterone levels can be suppressed with the provision of exogenous testosterone [12,13]. Here, we observed high levels of C-reactive protein and ferritin associated with reduced levels of total and bioavailable testosterone at the baseline. In addition, the low total and bioavailable testosterone and SHBG levels observed at baseline may be influenced by high BMI [21]. Although it is difficult to infer causality, after administration of exogenous testosterone, C-reactive protein and ferritin levels were reduced and total and bioavailable testosterone levels increased, which may have contributed to improved muscle function. For instance, keeping testosterone levels within the physiologic range has been shown to have a protective effect on forced expiratory volume and forced vital capacity [22]. In elderly patients with chronic heart failure, who are a frail population [23], Caminiti et al. found that testosterone replacement therapy improved peak oxygen consumption and respiratory function. We may hypothesize that an equivalent effect would occur in patients with COVID-19 who experience great skeletal muscle function deficits after ICU admission.

Exogenous administration of testosterone needs to be closely monitored because it may exacerbate benign prostatic hyperplasia and prostate cancer. No changes in prostate- 
specific antigen levels were observed (Table 1), and albumin levels were within 3.0 to $3.3 \mathrm{~g} / \mathrm{dL}$ during the time course. Furthermore, in patients with COVID-19, exogenous administration of testosterone can increase the risk of thrombosis [24], and therefore should not be administered to patients with known thromboembolic events. Here, leg and arm Doppler evaluation did not reveal thrombosis during the time course.

Exogenous administration of testosterone led to better diaphragm function in a male patient with COVID-19. Due to the nature of the study, causality was very low. However, this case report is a step forward for designing further clinical studies

\section{Conclusions}

Testosterone replacement therapy led to good diaphragm performance in a male patient with COVID-19. This should be interpreted with caution due to the exploratory nature of the study.

Author Contributions: Conceptualization, G.M., J.C.R.V., H.T., A.R.O.d.S., B.T., N.N.R., P.R.M.R. and P.L.S.; methodology, G.M., A.R.O.d.S. and N.N.R.; software, N.N.R.; validation, B.T.; formal analysis, G.M., J.C.R.V., H.T. and N.N.R.; investigation, G.M.; resources, G.M. and P.L.S.; data curation, A.R.O.d.S.; writing - original draft preparation, G.M. and P.L.S.; writing—review and editing, G.M., J.C.R.V., H.T., A.R.O.d.S., B.T., N.N.R., P.R.M.R. and P.L.S.; visualization, G.M. and P.L.S.; supervision, P.L.S.; project administration, P.R.M.R. and P.L.S.; funding acquisition, P.R.M.R. and P.L.S. All authors have read and agreed to the published version of the manuscript.

Funding: This research was funded by Brazilian Council for Scientific and Technological Development: 401700/2020-8; Brazilian Council for Scientific and Technological Development: 403485/2020-7; Rio de Janeiro State Research Foundation: E-26/210.181/2020; Rio de Janeiro State Research Foundation: E-26/010.002160/2019; Funding Authority for Studies and Projects: 01200008.00 and the APC was funded by Brazilian Council for Scientific and Technological Development: 403485/2020-7.

Institutional Review Board Statement: The study was conducted in accordance with the Declaration of Helsinki, and approved by the Ethics Committee board of Instituto D'Or de Pesquisa e Ensino (+5521 2109-8853) on 23 May 2021 for studies involving humans. Written informed consent was obtained from the patient.

Informed Consent Statement: Written informed consent was obtained from the patient(s) to publish this paper.

Data Availability Statement: The datasets analyzed for this study are available under communication with Author and Corresponding Author.

Acknowledgments: The authors would like to thank all the health workers directly involved in the case report.

Conflicts of Interest: The authors declare that the research was conducted in the absence of any commercial or financial relationships that could be construed as a potential conflict of interest.

\section{References}

1. Rastrelli, G.; Di Stasi, V.; Inglese, F.; Beccaria, M.; Garuti, M.; Di Costanzo, D.; Spreafico, F.; Greco, G.F.; Cervi, G.; Pecoriello, A.; et al. Low testosterone levels predict clinical adverse outcomes in SARS-CoV-2 pneumonia patients. Andrology 2020, 9, 88-98. [CrossRef] [PubMed]

2. Camici, M.; Zuppi, P.; Lorenzini, P.; Scarnecchia, L.; Pinnetti, C.; Cicalini, S.; Nicastri, E.; Petrosillo, N.; Palmieri, F.; D’Offizi, G.; et al. Role of testosterone in SARS-CoV-2 infection: A key pathogenic factor and a biomarker for severe pneumonia. Int. J. Infect. Dis. 2021, 108, 244-251. [CrossRef] [PubMed]

3. Gröner, M.F.; de Carvalho, R.C.; Camillo, J.; Ferreira, P.R.A.; Fraietta, R. Effects of COVID-19 on male reproductive system. Int. Braz. J. Urol. 2021, 47, 185-190. [CrossRef] [PubMed]

4. Hussain, A.N.; Hussain, F.; Hashmi, S.K. Role of testosterone in COVID-19 patients-A double-edged sword? Med. Hypotheses 2020, 144, 110287. [CrossRef]

5. Napolitano, L.; Barone, B.; Crocetto, F.; Capece, M.; La Rocca, R. The COVID-19 Pandemic: Is It A Wolf Consuming Fertility? Int J. Fertil. Steril. 2020, 14, 159-160. [CrossRef] [PubMed]

6. Palkar, A.; Narasimhan, M.; Greenberg, H.; Singh, K.; Koenig, S.; Mayo, P.; Gottesman, E. Diaphragm Excursion-Time Index: A New Parameter Using Ultrasonography to Predict Extubation Outcome. Chest 2018, 153, 1213-1220. [CrossRef] 
7. Bax, F.; Lettieri, C.; Marini, A.; Pellitteri, G.; Surcinelli, A.; Valente, M.; Budai, R.; Patruno, V.; Gigli, G.L. Clinical and neurophysiological characterization of muscular weakness in severe COVID-19. Neurol. Sci. 2021, 42, 2173-2178. [CrossRef]

8. Dalakas, M.C. Inflammatory myopathies: Update on diagnosis, pathogenesis and therapies, and COVID-19-related implications. Acta Myol. 2020, 39, 289-301. [CrossRef]

9. Islam, B.; Ahmed, M.; Islam, Z.; Begum, S.M. Severe acute myopathy following SARS-CoV-2 infection: A case report and review of recent literature. Skelet. Muscle 2021, 11, 1-7. [CrossRef]

10. Pasiakos, S.M.; Berryman, C.E.; Karl, J.P.; Lieberman, H.R.; Orr, J.S.; Margolis, L.M.; Caldwell, J.A.; Young, A.J.; Montano, M.A.; Evans, W.J.; et al. Effects of testosterone supplementation on body composition and lower-body muscle function during severe exercise- and diet-induced energy deficit: A proof-of-concept, single centre, randomised, double-blind, controlled trial. eBioMedicine 2019, 46, 411-422. [CrossRef]

11. Sattler, F.R.; Castaneda-Sceppa, C.; Binder, E.F.; Schroeder, E.T.; Wang, Y.; Bhasin, S.; Kawakubo, M.; Stewart, Y.; Yarasheski, K.E.; Ulloor, J.; et al. Testosterone and Growth Hormone Improve Body Composition and Muscle Performance in Older Men. J. Clin. Endocrinol. Metab. 2009, 94, 1991-2001. [CrossRef] [PubMed]

12. Vignozzi, L.; Cellai, I.; Santi, R.; Lombardelli, L.; Morelli, A.; Comeglio, P.; Filippi, S.; Logiodice, F.; Carini, M.; Nesi, G.; et al. Antiinflammatory effect of androgen receptor activation in human benign prostatic hyperplasia cells. J. Endocrinol. 2012, 214, 31-43. [CrossRef] [PubMed]

13. Mohamad, N.-V.; Wong, S.K.; Hasan, W.N.W.; Jolly, J.J.; Nur-Farhana, M.F.; Ima-Nirwana, S.; Chin, K.-Y. The relationship between circulating testosterone and inflammatory cytokines in men. Aging Male 2018, 22, 129-140. [CrossRef] [PubMed]

14. Vivier, E.; Dessap, A.M.; Dimassi, S.; Vargas, F.; Lyazidi, A.; Thille, A.W.; Brochard, L. Diaphragm ultrasonography to estimate the work of breathing during non-invasive ventilation. Intensiv. Care Med. 2012, 38, 796-803. [CrossRef]

15. Viveiros, A.; Rasmuson, J.; Vu, J.; Mulvagh, S.L.; Yip, C.Y.Y.; Norris, C.M.; Oudit, G.Y. Sex differences in COVID-19: Candidate pathways, genetics of ACE2, and sex hormones. Am. J. Physiol. Circ. Physiol. 2021, 320, H296-H304. [CrossRef]

16. Eshima, N.; Tokumaru, O.; Hara, S.; Bacal, K.; Korematsu, S.; Tabata, M.; Karukaya, S.; Yasui, Y.; Okabe, N.; Matsuishi, T. Sex- and Age-Related Differences in Morbidity Rates of 2009 Pandemic Influenza A H1N1 Virus of Swine Origin in Japan. PLoS ONE 2011, 6, e19409. [CrossRef]

17. Bienvenu, L.A.; Noonan, J.; Wang, X.; Peter, K. Higher mortality of COVID-19 in males: Sex differences in immune response and cardiovascular comorbidities. Cardiovasc. Res. 2020, 116, 2197-2206. [CrossRef]

18. Lucas, J.M.; Heinlein, C.; Kim, T.; Hernandez, S.A.; Malik, M.S.; True, L.D.; Morrissey, C.; Corey, E.; Montgomery, B.; Mostaghel, E.; et al. The Androgen-Regulated Protease TMPRSS2 Activates a Proteolytic Cascade Involving Components of the Tumor Microenvironment and Promotes Prostate Cancer Metastasis. Cancer Discov. 2014, 4, 1310-1325. [CrossRef]

19. Tomlins, S.A.; Rhodes, D.R.; Perner, S.; Dhanasekaran, S.M.; Mehra, R.; Sun, X.-W.; Varambally, S.; Cao, X.; Tchinda, J.; Kuefer, R.; et al. Recurrent Fusion of TMPRSS2 and ETS Transcription Factor Genes in Prostate Cancer. Science 2005, 310, 644-648. [CrossRef]

20. Muus, C.; The NHLBI LungMap Consortium; Luecken, M.D.; Eraslan, G.; Sikkema, L.; Waghray, A.; Heimberg, G.; Kobayashi, Y.; Vaishnav, E.D.; Subramanian, A.; et al. Single-cell meta-analysis of SARS-CoV-2 entry genes across tissues and demographics. Nat. Med. 2021, 27, 546-559. [CrossRef]

21. Diaz-Arjonilla, M.; Schwarcz, M.; Swerdloff, R.S.; Wang, C. Obesity, low testosterone levels and erectile dysfunction. Int. J. Impot. Res. 2008, 21, 89-98. [CrossRef]

22. Mohan, S.S.; Knuiman, M.; Divitini, M.L.; James, A.L.; Musk, A.W.; Handelsman, D.J.; Beilin, J.; Hunter, M.; Yeap, B.B. Higher serum testosterone and dihydrotestosterone, but not oestradiol, are independently associated with favourable indices of lung function in community-dwelling men. Clin. Endocrinol. 2015, 83, 268-276. [CrossRef] [PubMed]

23. Caminiti, G.; Volterrani, M.; Iellamo, F.; Marazzi, G.; Massaro, R.; Miceli, M.; Mammi, C.; Piepoli, M.; Fini, M.; Rosano, G.M. Effect of Long-Acting Testosterone Treatment on Functional Exercise Capacity, Skeletal Muscle Performance, Insulin Resistance, and Baroreflex Sensitivity in Elderly Patients with Chronic Heart Failure: A Double-Blind, Placebo-Controlled, Randomized Study. J. Am. Coll. Cardiol. 2009, 54, 919-927. [CrossRef] [PubMed]

24. Walker, R.F.; Zakai, N.A.; MacLehose, R.F.; Cowan, L.T.; Adam, T.J.; Alonso, A.; Lutsey, P.L. Association of Testosterone Therapy with Risk of Venous Thromboembolism among Men with and without Hypogonadism. JAMA Intern. Med. 2020, 180, 190. [CrossRef] [PubMed] 